\title{
CÍRCULO DE CULTURA COMO COMPONENTE QUALITATIVO DA PESQUISA EM EDUCAÇÃO FÍSICA: REFLEXÕES TEÓRICO- METODOLÓGICAS
}

\author{
Léo Barbosa Nepomuceno \\ Universidade Federal do Ceará, Fortaleza, Ceará, Brasil. \\ Jon Anderson Machado Cavalcante \\ Universidade da Integração Internacional da Lusofonia Afro-Brasileira, Acarape, Ceará, Brasil. \\ Luciana Venâncio \\ Universidade Federal do Ceará, Fortaleza, Ceará, Brasil. \\ Luiz Sanches Neto \\ Universidade Federal do Ceará, Fortaleza, Ceará, Brasil.
}

\begin{abstract}
Resumo
Este trabalho é uma reflexão teórico-metodológica que objetiva analisar o círculo de cultura como componente metodológico de pesquisas qualitativas em educação física. Delimitamos as etapas do círculo de cultura, seus objetivos e sua vinculação à perspectiva pedagógica de Paulo Freire. Realizamos revisão de literatura nas bases de dados Scientific Electronic Library Online (Scielo), Biblioteca Virtual em Saúde (BVS) e Redalyc. Destacamos o caráter participativo, dialógico e problematizador desse referencial metodológico, ressaltando sua dimensão ética e política. Sua utilização requer flexibilidade e reflexividade frente ao caráter participativo-dialógico das investigações.
\end{abstract}

Palavras-chave: Pesquisa Qualitativa. Educação. Metodologia. Pesquisa Participante.

\section{CULTURE CIRCLE AS A QUALITATIVE COMPONENT OF RESEARCH IN PHYSICAL EDUCATION: THEORETICAL-METHODOLOGICAL REFLECTIONS}

\begin{abstract}
The objective of this theoretical-methodological reflection is to analyze the culture circle as a methodological component of qualitative research in physical education. We have delimited the culture circle stages, its objectives and connections to the pedagogical perspective of Paulo Freire. We carried out literature review in the Scientific Electronic Library Online (Scielo), Virtual Health Library (BVS), and Redalyc databases. Then, we emphasize the participative, dialogical and problematizing character of this methodological reference, focusing on its ethical and political dimension. Its use requires flexibility and reflexivity in face of the participatory-dialogical character of the investigations.
\end{abstract}

Keywords: Qualitative Research. Education. Methodology. Participant Research. 


\title{
CÍRCULO DE CULTURA COMO COMPONENTE CUALITATIVO DE LA INVESTIGACIÓN EN EDUCACIÓN FÍSICA: REFLEXIONES TEÓRICO- METODOLÓGICAS
}

\begin{abstract}
Resumen:
Este trabajo es una reflexión teórico-metodológica que objetiva analizar el círculo de cultura como componente metodológico de investigaciones cualitativas en educación física. Delimitamos las etapas del círculo de cultura, sus objetivos y su vinculación a la perspectiva pedagógica de Paulo Freire. Para contextualizar la reflexión, realizamos revisión de literatura en las bases de datos Scientific Electronic Library Online (Scielo), Biblioteca Virtual en Salud (BVS) y Redalyc. Destacamos el carácter participativo, dialógico y problematizador de ese referencial metodológico, resaltando su dimensión ética y política. Su uso requiere flexibilidad y reflexividad frente al carácter participativo-dialógico de las investigaciones.
\end{abstract}

Palabras clave: Investigación Cualitativa. Educación. Metodología. Investigación Participante.

\section{Introdução}

A educação física pode ser compreendida como uma prática social subsidiada por conhecimentos científicos que se coadunam para explicá-la e dinamizá-la (BRACHT, 1997). Contudo, há controvérsias entre a dinâmica investigativa da educação física como prática científica e a sua dinâmica pedagógica como prática social (BETTI, 2005).

A pesquisa qualitativa adquire peculiaridades próprias à natureza sociocultural e histórica de seu objeto. Esse tipo de pesquisa volta-se para o estudo de realidades das quais cada pesquisador(a), em diferentes níveis, é agente ativo(a). Assim, a cientificidade ganha contornos de relatividade porque as teorias, conceitos, métodos e técnicas utilizadas adquirem sua legitimidade e validação, numa relação de coerência com os contextos em que se constrói o conhecimento. A não neutralidade da ciência evidencia-se como um pressuposto importante, tornando-se necessária a clareza sobre os interesses e valores que perpassam a produção do conhecimento (BOURDIEU, 2008, 2012; MINAYO, 2010, 2000). Além disso, a não linearidade também é um pressuposto no itinerário complexo de pesquisas qualitativas no campo da educação física (OVENS, BUTLER, HOPPER, 2013).

Desse modo, é necessário o exercício da reflexividade visando a manter uma postura (auto)crítica na construção dos objetos. É preciso que o(a) pesquisador(a) seja capaz de subordinar a utilização das técnicas e métodos à interrogação sobre condições e limites de validade (BOURDIEU, CHAMBOREDON e PASSERON, 2010; BOURDIEU, 2008, 2012).

A metodologia da pesquisa social, portanto, apresenta-se como "o caminho do pensamento e a prática exercida na abordagem da realidade" (MINAYO, 2000, p. 16), composto por teorias e técnicas articuladas, de modo criativo e original, num conjunto coerente de procedimentos capazes de dar conta dos impasses da elaboração do conhecimento (BRUYNE, HERMAN e SCHOUTHEETE, 1977). Vemos esse percurso como possibilidade para as investigações no campo da educação física como prática social. Diante da dinamicidade e flexibilidade das estratégias metodológicas, é de suma relevância o debate sobre a diversidade de possibilidades que se apresentam nos processos de investigação da realidade social e sua multiplicidade de alternativas.

Neste artigo, dentro da temática da metodologia qualitativa das pesquisas em educação física, nosso objetivo é analisar possibilidades de uso do círculo de cultura como componente metodológico de pesquisas, discutindo suas características e implicações de alguns de seus usos no processo de construção do conhecimento. $\mathrm{O}$ artigo justifica-se pela necessidade de 
implementação de métodos que se pautem na afirmação do compromisso da pesquisa frente aos sujeitos participantes, seus cotidianos e desafios da vida social. Assim, como alternativa aos recorrentes modelos metodológicos pautados somente em questionários ou entrevistas, afirmamos a importância de se discutir e implementar pesquisas com caráter participativo e baseadas em processos de inserção etnográfica.

\section{Itinerário metodológico}

De acordo com Luttrell (2010), é necessário explicitar a complexidade do itinerário qualitativo de pesquisa, o que implica analisar os critérios subjacentes a quaisquer modos de investigação. No intuito de contextualizar nossa reflexão, buscamos artigos nas bases de dados Scielo (Scientific Electronic Library Online), Biblioteca Virtual em Saúde (BVS) e Redalyc com a utilização do termo "círculo de cultura", visando a identificar experiências de utilização de tal referencial teórico-metodológico. Abordaremos, assim, alguns artigos que possibilitam adensar o debate teórico-metodológico proposto (BESERRA, ARAÚJO e BARROSO, 2006; BESERRA et al., 2011; BESERRA, PINHEIRO e BARROSO, 2008; FERNANDES e BACKES, 2010; HEIDEMANN et al., 2010; MEDEIROS et al., 2010; MONTEIRO e VIEIRA, 2010). Entendemos que essa delimitação temática foi necessária para o propósito deste artigo, embora tenhamos identificado e selecionado poucos trabalhos em decorrência dessa especificidade. Revisamos obras de e sobre Paulo Freire para delimitar sistematicamente as etapas do círculo de cultura, seus objetivos e sua vinculação com algumas ideias pedagógicas.

Para a organização do material analisado, optamos por apresentar inicialmente a caracterização e três fases do círculo de cultura, de modo a delimitar idiossincrasias metodológicas desse referencial. A seguir, discutimos algumas possibilidades viáveis à investigação qualitativa em campos convergentes às dinâmicas da educação física. Analisamos algumas similaridades e distinções diante de outros referenciais. Posteriormente, analisamos algumas possibilidades de uso do círculo de cultura como componente metodológico de pesquisas em educação física, discutindo alcances da utilização, características e implicações no processo de elaboração do conhecimento.

\section{Caracterização e fases do círculo de cultura}

O círculo de cultura é uma metodologia de trabalho com grupos, criada por Paulo Freire (FREIRE, 1979; GÓIS, 2003; NASCIMENTO, 2005), originalmente para a alfabetização de adultos. O desenvolvimento dessa perspectiva educativa repercutiu na ampliação do uso do círculo de cultura para vários contextos do trabalho social, tornando-se um componente metodológico para pesquisas com abordagens qualitativas em diferentes áreas.

O círculo de cultura, desde sua origem, constitui-se principalmente como processo grupal dialógico, que busca operacionalizar-se na horizontalidade das relações e liberdade de expressão, assim como no processo problematizador da realidade social vivida no cotidiano pelos(as) participantes. É uma proposta de atividade pedagógica que expressa um método ativo, dialogal e participante de educação, voltado para a formação de sujeitos críticos e reflexivos (FREIRE, 1994; BRANDÃO, 2006). Tem como caracterizadores principais: o diálogo e a linguagem articulados à experiência cotidiana dos(as) participantes e à problematização de conhecimentos potencializadores de mudanças sociais. O círculo de cultura expressa a concepção de ser humano e educação, no pensamento de Paulo Freire, em que "nenhuma ação educativa pode prescindir de uma reflexão sobre o homem e de uma 
análise sobre suas condições culturais" (FREIRE, 1994, p. 61), considerando homens e mulheres situados num tempo e espaço sociais, históricos e culturais (HOOKS, 2013).

O círculo de cultura operacionaliza-se a partir de uma "inserção etnográfica" inicial, que é a fase de levantamento vocabular ou "levantamento do universo vocabular" (FREIRE, 1994), nos contextos de convivência dos(as) participantes. Nessa fase, utiliza-se a observação participante para realizar levantamento de temas, palavras e questões representativas para a cultura local. O material construído (palavras, temas, questões e imagens) deve ser contextual, particular e de forte sentido existencial para os(as) participantes, deve ser representativo da história já vivida no lugar e conter expressões típicas do povo, constituindo-se como instrumentos mediadores para releitura coletiva da realidade social (BRANDÃO, 2006; FREIRE, 1980). No processo de letramento de adultos, fonte originária da proposta do círculo de cultura, o levantamento vocabular produz um conjunto de palavras ou temas geradores, os quais serão selecionados, numa segunda fase.

A segunda etapa é chamada de fase de elaboração de temas geradores. Nesta fase, são construídos/elaborados temas a partir dos seguintes critérios semiológicos: a riqueza silábica; dificuldade fonética da língua; e densidade de sentido pragmático. As palavras ou temas devem ser propiciadores da leitura da língua e da leitura do mundo porque se pautam no reconhecimento do potencial pedagógico e transformador do exercício do diálogo sobre uma dada realidade social compartilhada (BRANDÃO, 2006; FREIRE, 1980).

Os temas geradores reunidos devem representar uma unidade epocal, um contexto situacional complexo, e serem elementos mediadores do diálogo sobre o contexto a ser analisado. Nesse sentido, podemos inferir que os temas geradores propostos por Freire (2011), assim como sua forma de entendimento de mundo, continuam relevantes do ponto de vista pedagógico, epistemológico e político (FRANCO, 2017).

A terceira fase consiste na criação de "situações sociológicas" ou "situações existenciais típicas", que funcionam como desafios pedagógicos para os grupos e articulam a alfabetização com o processo de conscientização (FREIRE, 1980, 1994). São situações locais cotidianas, que podem ser pintadas, desenhadas ou fotografadas, "[...] que abrem perspectivas para a análise de problemas nacionais e regionais. Entre estas perspectivas se situam as palavras geradoras, ordenadas conforme o grau de suas dificuldades fonéticas" (FREIRE, 1980, p.44).

Uma palavra geradora pode tanto referir-se à situação como um todo ou, parcialmente, referir-se a um de seus elementos. Após a seleção do material e das situações, são elaboradas fichas auxiliares para os(as) educadores(as), de modo a organizar o processo pedagógico com sugestões e indicações para o trabalho de debate junto ao grupo, a partir da associação de palavras, temas e situações. Formam-se núcleos de questões com dimensões existenciais, ligadas à vida, às políticas, ou seja, aos determinantes sociais das condições de vida (BRANDÃO, 2006; FREIRE, 1980, 1994, 2011). Portanto, criam-se as condições para o desenvolvimento de atividades pedagógicas e espaços interativos, nos quais se dialoga sobre a experiência dos(as) participantes com os referidos temas e palavras, articulando aspectos técnicos e políticos da aprendizagem da leitura e da escrita.

\section{Potencialidades do círculo de cultura na pesquisa qualitativa}

A investigação coletiva dos temas geradores deve avançar no sentido do aprofundamento de uma compreensão crítica dos(as) envolvidos(as) sobre o contexto da vida social compartilhada. Por meio de processos de codificação e decodificação de situações existenciais concretas, a compreensão dos sujeitos sobre as práticas sociais é trabalhada na perspectiva de ampliar percepções coletivas e individuais. Nesse processo, o diálogo problematizador destaca-se como elemento orientador do modo como as atividades do círculo 
de cultura são conduzidas. Ele se expressa numa atitude dialógica comprometida com a construção coletiva da transformação da realidade, buscando a superação de relações antagônicas (contrárias ao diálogo) e desumanizadoras, que se concretizam pela manipulação e imposição de valores e ideias. Há, no diálogo, relações horizontais de intercâmbio de saberes no encontro mediatizado pelo mundo (FREIRE, 1994). A problematização, assim, é um processo que perpassará a realização da atividade grupal no círculo de cultura e tem grande potencial para gerar situações em que as pessoas sejam convidadas ou estimuladas, face ao diálogo e exercício da reflexividade, a revisar ações e opiniões sobre a vida cotidiana (MONTERO, 2006).

As bases caracterizadoras do processo problematizador são: exercício do escutar; comunicar; cuidar do diálogo grupal; humildade e respeito pelo(a) outro(a); troca de saberes; exercício da análise crítica; referência a situações reais; aprofundamento da conscientização dos(as) participantes; foco no processo de aprendizagem, buscando níveis mais aprofundados de entendimento; caráter reflexivo; construção coletiva; exercício de suspensão de cargos e status, valorizando a horizontalidade das relações; possibilidade de elaboração de sínteses; possibilidade de levar a transformações da realidade problematizada, sendo mobilizadora de ações (MONTERO, 2006; ANDRADE, 2003).

Ao apontar para uma revisão e transformação dos saberes e das práticas dos(as) participantes, o círculo de cultura, como método de investigação e transformação da realidade social, implica não em um processo instrucional - a educação bancária - mas de recursividade entre pesquisa e ação. Afinal, em sua expressão plena, a educação em Freire (2011) envolve uma ressignificação coletiva do mundo através de uma práxis libertadora. Tais elementos são contributos pertinentes para os processos de produção do conhecimento ao integrar o que Pedro Demo (2009, p. 32) afirma como "critérios políticos de demarcação científica", pois apontam uma reflexão crítica acerca das possibilidades de socialização e de usos do saber, bem como das relações de poder presentes e suscitadas em sua construção.

Diante dos apontamentos mencionados acima, no contexto da abordagem qualitativa de pesquisa, o círculo de cultura pode ser utilizado como componente facilitador de diversas linhas investigativas. É uma estratégia metodológica que propicia uma variedade nos modos de construção de material empírico, capaz de dar consistência a uma gama de estudos sobre fenômenos significativos que envolvem as convergências entre as dinâmicas da cultura, movimento, corpo e ambiente. Sua potencialidade se dá pela articulação de processos etnográficos e conversacionais na geração participativa de indícios sobre trajetórias socioculturais coletivas. Dialogicamente, esses indícios constituem-se como saberes e conceituações por parte dos(as) participantes, que são concebidos, de modo não linear, como produtores de conhecimento.

Essa estratégia metodológica possibilita o surgimento e a utilização de uma diversidade de linguagens, ao ampliar as formas de expressão dos(as) participantes e registro de suas significações. Isto pode favorecer uma postura mais autêntica e espontânea diante das questões e temas de pesquisa. Decorre daí uma perspectiva variada de materiais empíricos como: sistematizações de diários de campo, produção de vídeos e gravações de áudio, bem como de construções coletivas de textos e outros materiais. Os diários de campo podem ser produzidos a partir da experiência de inserção etnográfica no campo. Na fase inicial de levantamento vocabular, os diários destacam questões e temas pertinentes ao contexto sociocultural investigado. Potencializam também o processo (auto)reflexivo vivenciado no estreitamento da relação com o objeto de pesquisa. Os vídeos e gravações podem ser produzidos tanto na fase de levantamento vocabular, como nas atividades grupais do círculo de cultura.

A incorporação do círculo de cultura como elemento metodológico tem, como consequência ético-epistemológica, o entendimento de que os(as) participantes da pesquisa 
são agentes ativos. No decorrer do estudo, cada participante influi diretamente na direção para onde aponta a construção do conhecimento e, por isso, a pesquisa tem caráter formativo. No campo da pesquisa educacional, por exemplo, parece que há uma aproximação consistente nos pressupostos formativos entre a problematização do círculo de cultura e a espiralidade da pesquisa-ação (PIMENTA e FRANCO, 2008).

A valorização dos(as) participantes como agentes aponta para o reconhecimento de que são sujeitos epistêmicos da pesquisa. Para Charlot (2000), esse reconhecimento é subjacente à relação que cada sujeito estabelece com o saber. Nesse sentido, o(a) pesquisador(a) deve ser um(a) agente comprometido(a) ética e politicamente com a transformação da realidade social estudada, onde os(as) participantes devem ser considerados como sujeitos de saber. A produção do conhecimento, nessa perspectiva, deve buscar a relevância social e existencial para os(as) envolvidos(as), revelando aspectos da vida em que se entrelaçam dimensões afetivas, étnicas, espirituais, identitárias etc.

A utilização desse referencial metodológico no contexto da investigação qualitativa torna necessária a adaptação do trabalho com grupos, bem como uma postura flexível capaz de abrir-se dialogicamente à interlocução com os(as) participantes. Essa abertura é pertinente às pesquisas de cunho etnográfico, por exemplo, com uma ampla gama de experiências de inserção em grupos específicos, dentro de uma lógica ativa e participativa de construção do conhecimento (CAPRARA e LANDIM, 2008; FERNANDES e BACKES, 2010; HEIDEMANN et al., 2010).

Essa abertura à participação e intencionalidade de mudança social deve influir na construção do objeto de pesquisa. No entanto, deve preservar o distanciamento crítico e reflexivo necessário para a elaboração de conhecimentos científicos situados no contexto político-ideológico da investigação. Desse modo, é preciso percorrer um caminho intermediário, que transita entre a proximidade dos encontros com o(a) outro(a) e a distância ou assimetria decorrentes de quem é um(a) cientista no meio de outros(as) cientistas (GEERTZ, 2009).

Em síntese, percebe-se que o caráter participativo, ativo e dialogal do círculo de cultura, coloca-o como possibilidade metodológica apropriada para atividades de pesquisaação. Os processos investigativos da pesquisa-ação são realizados em associação com objetivos de intervenção ou resolução de problemas coletivos, a partir de relações de cooperação entre pesquisadores(as) e participantes representativos(as) da situação problemática (THIOLLENT, 2009). Essa perspectiva contribui, por exemplo, nos campos da educação em saúde (FERNANDES e BACKES, 2010; HEIDEMANN et al., 2010; SILVA et al., 2010; MONTEIRO e VIEIRA, 2010), educação permanente (MEDEIROS et al., 2010), práticas comunitárias (GÓIS, 2008), educação popular (VASCONCELOS, 2001) e educação física escolar (BETTI, 2009; BRACHT et al., 2003).

Desse modo, entendemos que a utilização do círculo de cultura apresenta-se como alternativa interessante e pertinente na pesquisa qualitativa, que possibilita: construção de conhecimento e desenvolvimento de linhas interpretativas e de intervenção - a partir de processos participativos articuladores de diversos saberes e práticas.

\section{Perspectivas de pesquisas com círculo de cultura}

Há, aparentemente, pouco reconhecimento da potencialidade do círculo de cultura como instrumental metodológico de pesquisas, expresso no limitado número de pesquisas publicadas. No entanto, sua adoção vem sendo realizada por investigações qualitativas em alguns campos, como na educação, saúde e ciências humanas. 
Na educação biocêntrica (ANDRADE, 2003) e na psicologia comunitária (GÓIS, 2003), por exemplo, o círculo de cultura tem relevância não somente metodológica, mas, sobretudo, teórico-epistemológica, já que está articulado à concepção freireana de educação.

Esta ênfase refere-se às metodologias de viés participativo e interventivo que trazem em seus princípios ou procedimentos influências do círculo de cultura. Tais proposições explicitam o que Demo (2009, p. 33) aponta acerca da relação entre saber e poder: "Poderíamos partir da idéia de politicidade, típica da obra de Paulo Freire [...] Significa o espaço do sujeito como ator [...] que é capaz de criar para além daquele que encontra dado em sua história ou inerente em seu processo evolucionário".

Mediante essa dimensão política é que se destacam, na área da educação, as influências do círculo de cultura nas chamadas perspectivas de pesquisa engajada. Segundo Figueiredo (2004), elas se referem a metodologias inspiradas no círculo de cultura, em especial, no compromisso com o diálogo no processo de investigação-intervenção e de construção dos saberes e das realidades dos/as participantes.

Nesse aspecto, Figueiredo (2004) aponta que as pesquisas engajadas dizem respeito a metodologias e experiências em que convergem integralmente os atos de pesquisa, educativo e político. Assim, a ênfase na análise dos caminhos do engajamento no processo investigativo já se encontra nos fundamentos da pesquisa participante - quando destaca o contato entre diferentes cosmovisões sobre o objeto e a consideração dos(as) participantes da pesquisa como sujeitos construtores de conhecimento - e, como mencionado, da pesquisa-ação - com a análise de um problema emergente de situações concretas e contextuais, e a busca coletiva e dialógica por sua transformação.

Além dessas perspectivas, Figueiredo (2004) reconhece, dentro do campo da pesquisa engajada, a sociopoética, um método elaborado por Iraci dos Santos e Jacque Gauthier (1999), com presença maior nas áreas da Educação e da Enfermagem. Esse método traz o círculo de cultura como horizonte de construção do grupo-pesquisador, formado pelos(as) participantes, por meio do qual, busca-se uma democratização das relações entre os saberes acerca do tema de pesquisa, com a maior visibilidade de suas diversas racionalidades, linguagens e semânticas.

Esses diferentes horizontes e experiências metodológicas trazem em suas lógicas epistêmicas os fundamentos do diálogo problematizador do círculo de cultura de Freire como mediador da co-construção descolonizadora do conhecimento e da realidade (FIGUEIREDO, 2004). São características da "politicidade", a permear as práticas de pesquisa envoltas de temáticas marcadas por relações de opressão, a exigência tanto uma reconstrução dos saberes quanto das ações diante dessa realidade (DEMO, 2009).

Destacam-se, ainda, outras duas perspectivas de uso desse referencial teóricometodológico que se pautam na dialogicidade como princípio orientador da construção do conhecimento, com ênfase na integração entre narrativas biográficas, processos formativos e de intervenção: o círculo ecobiográfico, gestado em Ferreira (2011) e o círculo reflexivo biográfico, proposto por Olinda (2010).

Nessas metolodologias, as características da pesquisa engajada podem ser encontradas, entretanto, adquire relevo as singularidades semânticas expostas nas narrativas e aprendizagens originadas nas interlocuções entre os/as participantes. De modo que, o diálogo problematizador, presente no círculo de cultura de Paulo Freire, medeia a construção e partilha das narrativas de histórias de vida e a tessitura formativa que emergem dos temas e contextos dos(as) participantes da pesquisa.

O círculo ecobiográfico integra as proposições epistêmicas do círculo de cultura, com destaque para a dialogicidade entre os(as) participantes em torno do tema pesquisado. Mas articula esse princípio junto ao processo de construção de narrativas biográficas e de apreensão das relações entre os sujeitos e o ambiente. Ele surge nos encontros 
interdisciplinares entre a educação ambiental dialógica (CARDOSO e FIGUEIREDO, 2012) e a psicologia social, tendo como diferencial a articulação entre a produção de saberes acerca da realidade vivida pelos(as) participantes e a elaboração e partilha de suas histórias de vida em um dado ambiente. $\mathrm{O}$ destaque maior dessa perspectiva encontra-se na compreensão sobre o modo com que os afetos contribuem para os vínculos e as ressignificações necessárias para a transformação dos saberes, das relações e das práticas (FERREIRA, 2011).

Por sua vez, o círculo reflexivo biográfico (OLINDA, 2010), além de convergir com o horizonte educacional de Freire (1996) ao integrar a formação à experiência de pesquisa, também se fundamenta no diálogo como postura e mediação das partilhas de narrativas entre os(as) participantes. Surge, portanto, do entrelaçamento dos estudos sobre histórias de vida e formação com a noção de narrativa de Paul Ricoeur e com o círculo de cultura de Freire (OLINDA e SOUSA, 2012).

Nessa estratégia metodológica, o diferencial encontra-se na utilização dos preceitos metodológicos do círculo de cultura para o aprofundamento das significações emergentes nas narrativas acerca do tema de pesquisa. É o que Olinda e Sousa (2012) identificam como "círculos reflexivos temáticos", o momento desse delineamento em que se busca ampliar a dialogicidade entre os(as) participantes e suas elaborações biográficas acerca do tema investigado. Essas duas perspectivas têm em comum a integração entre o processo participativo e dialógico de produção de saberes no círculo de cultura e a construção de narrativas biográficas enunciadoras das singularidades em torno do tema de pesquisa, mediador dos encontros entre os(as) participantes.

\section{Perspectivas para a pesquisa em Educação Física a partir do círculo de cultura}

Conforme Kunz (1991), as concepções críticas da educação física necessitam superar suas próprias limitações teóricas em favor de alternativas pedagógicas para que não percam sua ressonância crítica. Há necessidade de que a ação pedagógica fomente a elaboração crítica do saber, como forma de luta ideológica, e nesse sentido o círculo de cultura pode contribuir para que se busque a criticidade a partir da explicitação de experiências ou da discussão de vivências corporais compartilhadas em situações de aprendizagem. O uso do círculo de cultura na educação física proporciona possibilidades de diversificação nos itinerários metodológicos de pesquisa, privilegiando a prática da observação participante e a produção de conhecimentos baseados na vivência dos sujeitos envolvidos. Assim, o trabalho de construção coletiva de conhecimentos em educação física encontra nessa proposta metodológica uma alternativa relevante.

De acordo com Bracht (1997), a assim chamada educação física revolucionária traz uma concepção crítica da educação física de forma bastante difusa, apresentando-se ainda muito fragmentada. O que diferencia essa perspectiva de outras é o fato de realizar a crítica da educação física a partir de sua contextualização na sociedade capitalista. A crítica advém da tradição teórica do marxismo e, assim, ressalta a dimensão política da educação e da educação física.

Para que se promova avanço qualitativo na educação física, Bracht (1997, p. 27) aponta que há necessidade de "um compromisso político com as classes oprimidas, com vistas a transformações estruturais na sociedade", e que essa é uma condição indispensável para o convívio humano. Há dois pontos que merecem a análise crítica, segundo Bracht (1997): a ideologia burguesa veiculada pela educação física e a "domesticação do corpo". Ambos os pontos apontam para a necessidade de transformação a partir das demandas complexas de cada contexto sociocultural.

As formas de abordar a complexidade dos processos formativos na educação física requerem "criatividade metodológica" por parte dos(as) pesquisadores(as). Isso não significa, 
contudo, que seja necessário "reinventar a roda" ao se propor itinerários qualitativos de pesquisa. Porém, sinaliza a necessidade de abertura de caminhos convergentes entre proposições teóricas e metodológicas, bem como a consideração das demandas ampliadas do ambiente sociocultural (SANCHES NETO et al., 2013). O círculo de cultura, como alternativa metodológica possibilita uma coerência com perspectivas críticas e criativas de intervir nos processos formativos em educação física.

Nesse sentido, encontramos formas de abordar a aprendizagem dos(as) alunos(as) a partir das aulas de educação física na educação básica, que foram concretizadas a partir de contribuições de Charlot (2000), Freire (1996) e Kunz (1991). A relação que os(as) alunos(as) estabeleceram com os seus próprios saberes indicou modos compartilhados de elaboração dos conhecimentos, que valorizam estratégias investigativas coletivas em grupos e pressupostos educativos freireanos.

Além disso, a busca constante por autonomia, emancipação e pelo fomento à criticidade dos sujeitos seriam indícios da perspectiva freireana em investigações situadas na educação física no processo de escolarização (BETTI et al., 2014). Por isso, Bossle e Molina Neto (2009) apontam a necessidade de os(as) estudantes da educação básica participarem do processo de planejamento e de construção das aulas, de modo a romper com o modelo de educação bancária, porque a ética discursiva é baseada na responsabilidade coletiva.

\section{Considerações finais}

Nosso levantamento bibliográfico revelou que a temática do círculo de cultura tem sido tratada em poucas publicações que contemplam de modo aprofundado o uso dessa metodologia no campo da pesquisa qualitativa em educação física (AGUIAR, 2014; SILVA e MARTINS, 2015). Tais achados revelam que, embora seja uma metodologia de trabalho consagrada com grupos no campo da educação, o círculo de cultura ainda é pouco utilizado para fins de pesquisa na educação física, tornando ainda incipiente o debate sobre as possibilidades e implicações de suas possíveis incorporações e adaptações.

É evidente, no entanto, a riqueza do círculo de cultura como instrumental de produção de conhecimento no campo das ciências sociais e humanas, especialmente como método de abordagem qualitativa da realidade social, com importantes contribuições para pesquisa e intervenção nos setores da educação e da saúde. Contraditoriamente, a educação física tem relações convergentes com as ciências humanas e sociais, assim como a educação e a saúde.

Consideramos que o círculo de cultura é um potente referencial para o desenvolvimento de pesquisas qualitativas na educação física, especialmente para o aporte de estratégias metodológicas baseadas em práticas colaborativas de produção de saberes compartilhados, contextualizados e críticos. Sua utilização, no entanto, requer a compreensão das fases de realização, sua necessária adaptação criativa aos objetivos da pesquisa e/ou intervenção, abertura flexível ao caráter participativo-dialógico do processo investigativo, rigorosa reflexividade para alcançar o equilíbrio entre aproximação e distanciamento frente à realidade social analisada.

\section{Referências}

AGUIAR, A. A. D. Círculo de cultura: intervenção pedagógica na educação física. In: Encontro Nacional de Didática e Prática de Ensino. Anais [...]. 2014. Didática e prática de ensino na relação com a formação de professores, 2014. 
ANDRADE, C. R. X. Educação biocêntrica: vivenciando o desenvolvimento organizacional. Fortaleza: Banco do Nordeste, 2003.

BESERRA, E. P.; ARAÚJO, M. F. M.; BARROSO, M. G. T. Promoção da saúde em doenças transmissíveis - uma investigação entre adolescentes. Acta Paulista de Enfermagem, v. 19, n. 4, p. 402-407, 2006.

BESERRA, E. P.; PINHEIRO, P. N. C.; BARROSO, M. G. T. Ação educativa do enfermeiro na prevenção de doenças sexualmente transmissíveis: uma investigação a partir das adolescentes. Esc. Anna Nery Rev Enferm, v. 12, n. 3, p.522-28, set. 2008.

BESERRA, E. P.; TORRES, C. A.; PINHEIRO, P. N. C.; ALVES, M. D. S.; BARROSO, M. G. T. Pedagogia freireana como método de prevenção de doenças. Ciência \& Saúde Coletiva, v. 16, supl. 1, p.1563-1570, 2011.

BETTI, M. Educação física como prática científica e prática pedagógica: reflexões à luz da filosofia da ciência. Revista Brasileira de Educação Física e Esporte, v. 19, n. 3, p.183-197, jul./set. 2005. DOI: http://dx.doi.org/10.1590/S1807-55092005000300002

BETTI, M. Educação física escolar: ensino e pesquisa-ação. Ijuí-RS: Unijuí, 2009.

BETTI, M. et al. Fundamentos filosóficos e antropológicos da teoria do se-movimentar e a formação de sujeitos emancipados, autônomos e críticos: o exemplo do currículo de educação física do Estado de São Paulo. Movimento, v. 20, n. 4, p. 1631-1653, out./dez. 2014. DOI: $10.22456 / 1982-8918.46732$

BOSSLE, F.; MOLINA NETO, V. Leituras para (re)pensar o trabalho coletivo dos professores de educação física. Movimento, v. 15, n. 3, p. 89-107, jul./set. 2009. DOI: $\underline{10.22456 / 1982-8918.6877}$

BOURDIEU, P. Para uma sociologia da ciência. Lisboa: Edições 70, 2008.

BOURDIEU, P. Poder simbólico. 16. ed. Rio de Janeiro: Bertrand Brasil, 2012.

BOURDIEU, P.; CHAMBOREDON, J.C; PASSERON, J.C. Ofício de sociólogo: metodologia da pesquisa na sociologia. 7. ed. Petrópolis: Vozes, 2010.

BRACHT, V. Educação física e aprendizagem social. 2. ed. São Paulo: Magister, 1997.

BRACHT, V.; CAPARROZ, F. E.; FONTE, S. S. D.; FRADE, J. C.; PAIVA, F.; PIRES, R. Pesquisa em ação: educação física na escola. Ijuí-RS: Unijuí, 2003.

BRANDÃO, C.R. O que é Método Paulo Freire. 20. ed. São Paulo: Brasiliense , 2006. (Coleção Primeiros Passos).

BRUYNE, P.; HERMAN, J.; SCHOUTHEETE, M. Dinâmica da pesquisa em ciências sociais: os pólos da prática metodológica. Rio de Janeiro: Francisco Alves, 1977.

CAPRARA, A.; LANDIM, L.P. Etnografia: uso, potencialidades e limites na pesquisa em saúde. Interface - Comunic., Saúde, Educ., v. 12, n. 25, p.363-376, abr/jun, 2008. 
CHARLOT, B. Da relação com o saber: elementos para uma teoria. Porto Alegre: Artmed, 2000 .

DEMO, P. Metodologia do Conhecimento Científico. São Paulo: Atlas, 2009.

FERNANDES, M.C.P.; BACKES, V.M.S. Educação em saúde: perspectivas de uma equipe da Estratégia Saúde da Família sob a óptica de Paulo Freire. Revista Brasileira de Enfermagem, v. 63, n. 4, p.567-573, Brasília, jul./ago. 2010.

FERREIRA, K. P. M. A formação de sentido e o sentido da vida: o Círculo Ecobiográfico com educadores e as experiências afetivas formadoras em sua relação com o semiárido cearense. 2011. 190 f. Tese (Doutorado em Educação Brasileira) - Centro de Humanidades, Universidade Federal do Ceará, Fortaleza, 2011.

FIGUEIREDO, J. B. A. Educação ambiental dialógica e colonialidade da natureza ambiental. In: DIAS, A. A.; MACHADO, C. J. S.; NUNES, M.L.S. Educação, direitos humanos e inclusão social: currículo, formação docente e diversidade sociocultural. João Pessoa-PB: Editora Universitária da UFPB, 2009.

FIGUEIREDO, J. B. A. Pesquisa engajada e intervenção em educação ambiental dialógica. In: $27^{\text {a }}$ Reunião Anual da ANPED. Caxambu-MG. 21 a 24 de novembro de 2004. Anais [...]. Disponível em: http://27reuniao.anped.org.br/gt22/t224.pdf. Acesso em: 28 abr. 2018.

CARDOSO, A. M. F.; FIGUEIREDO, J. B. A. Interfaces da perspectiva eco-relacional e do método (auto)biográfico na pesquisa em educação ambiental dialógica. In: OLINDA, E. M. B. Artes do sentir: trajetórias de vida e formação. Fortaleza-CE: Edições UFC, 2012.

FRANCO, M. A. R. S. Da necessidade/atualidade da pedagogia crítica: contributos de Paulo Freire. Reflexão e Ação, v. 25, n. 2, p. 154-170, maio/ago. 2017. DOI: $\underline{10.17058 / \text { rea.v25i2.8891 }}$

FREIRE, P. Conscientização: teoria e prática da libertação. Uma introdução ao pensamento de Paulo Freire. São Paulo: Editora Moraes, 1980.

FREIRE, P. Educação como prática de liberdade. 9. ed. Rio de Janeiro: Paz e Terra, 1979.

FREIRE, P. Educação e mudança. 20. ed. Rio de Janeiro: Paz e Terra, 1994.

FREIRE, P. Pedagogia da autonomia: saberes necessários à prática educativa. São Paulo: Paz e Terra, 1996.

FREIRE, P. Pedagogia do oprimido. 50. ed. São Paulo: Paz e Terra, 2011.

GAUTHIER, J. Sociopoética: encontro entre arte, ciência e democracia na pesquisa em ciências humanas e sociais, enfermagem e educação. Rio de Janeiro: Anna Nery-UFRJ, 1999.

GEERTZ, C. Obras e vidas: o antropólogo como autor. 3. ed. Rio de Janeiro: Editora UFRJ, 2009. 
GÓIS, C.W.L. Psicologia comunitária no Ceará: uma caminhada. Fortaleza: Publicações Instituto Paulo Freire, 2003.

GÓIS, C.W.L. Saúde comunitária: pensar e fazer. São Paulo: HUCITEC, 2008.

HEIDEMANN, I.B.S. et al. Incorporação teórico-conceitual e metodológica do educador Paulo Freire na pesquisa. Revista Brasileira de Enfermagem, v. 63, n. 3, p.416-420, Brasília, maio-jun. 2010.

HOOKS, B. Ensinando a transgredir: a educação como prática da liberdade. São Paulo: WMF-Martins Fontes, 2013.

KUNZ, E. Transformação didático-pedagógica do esporte. Ijuí-RS: Unijuí, 1991.

LUTTRELL, W. (org.). Qualitative educational research: readings in reflexive methodology and transformative practice. New York: Routledge, 2010.

MEDEIROS, A. C.; PEREIRA, Q. L. C.; SIQUEIRA, H. C. H.; CECAGNO, D.; MORAES, C. L. Gestão participativa na educação permanente em saúde: olhar das enfermeiras. Revista Brasileira de Enfermagem. Brasília. v. 63, n. 1, p.38-42, jan./fev. 2010.

MINAYO, M. C. S. O desafio do conhecimento: pesquisa qualitativa em saúde. 12. ed. (revista e aprimorada). São Paulo: HUCITEC, 2010.

MINAYO, M. C. S. Ciência, técnica e arte: o desafio da pesquisa social. In: MYNAIO, M. C. S. (org.) Pesquisa social: teoria, método e criatividade. 17. ed. Petrópolis: Editora Vozes, 2000 .

MONTEIRO, E.M.L.M.; VIEIRA, N.F.C. Educação em saúde a partir de círculos de cultura. Revista Brasileira de Enfermagem. v. 63, n 3, p.397-403, Brasília, maio/jun. 2010.

MONTERO, M. Hacer para transformar: el metodo en la psicología comunitária. Buenos Aires: Paidós, 2006.

NASCIMENTO, L. M. J. Ler as palavras, ler o mundo. Paulo Freire: a utopia do saber. Coleção Memória da Pedagogia. Viver Mente \& Cérebro, n. 4, São Paulo: Duetto Editorial, 2005.

OLINDA, E. M. B.; SOUSA, E. F. Aprendizagens Experienciais no Círculo Reflexivo Biográfico: aprendendo a ouvir e a estar junto. In: OLINDA, E. M. B. Artes do sentir: trajetórias de vida e formação. Fortaleza-CE: Edições UFC, 2012.

OLINDA, E. M. B. Círculo Reflexivo Biográfico: dispositivo de pesquisa e de formação. São Paulo: Anais do IV CIPA, 2010.

OVENS, A.; BUTLER, J.; HOPPER, T. (orgs.). Complexity thinking in physical education: reframing curriculum, pedagogy and research. Londres: Routledge, 2013.

PIMENTA, S. G.; FRANCO, M. A. S. Pesquisa em educação: possibilidades investigativas/formativas da pesquisa-ação. São Paulo: Loyola, 2008. 
SANCHES NETO, L. et al. Demandas ambientais na educação física escolar: perspectivas de adaptação e de transformação. Movimento, Rio Grande do Sul, v. 19, n. 4, p. 309-330, out./dez. 2013. DOI: 10.22456/1982-8918.41079

SILVA, M. E. H.; MARTINS, R. M. Dialogicidade na educação física nas escolas estaduais de ensino médio no município de Caucaia no Ceará. In: Anais [...]. III Seminário Internacional Diálogos com Paulo Freire. Natal: UFRN, 2015, p. 433-442.

SILVA, K. L.; DIAS, F. L. A.; MAIA, C. C.; PEREIRA, D. C. R.; VIEIRA, N. F. C.; PINHEIRO, P. N. C. A influência das crenças e valores culturais no comportamento sexual dos adolescentes do sexo masculino. Revista de Enfermagem UERJ, Rio de Janeiro, v. 18, n. 2, p. 247-252, abr./jun. 2010.

THIOLLENT, M. Metodologia da pesquisa-ação. 17. ed. São Paulo: Cortez, 2009.

VASCONCELOS, E. M. Redefinindo as práticas de saúde a partir de experiências de educação popular nos serviços de saúde. Interface-Comunicação, Saúde, Educação. Botucatu-SP, v. 5, n. 8, 2001.

Recebido em: 21/10/2018

Revisado em: 14/01/2019

Aprovado em: 15/04/2019

Endereço para correspondência:

leobnepomuceno@hotmail.com

Léo Barbosa Nepomuceno

Universidade Federal do Ceará, Instituto de Educação Física e Esportes.

Avenida Mister Hull, Parque Esportivo, Bloco 320

Campus do Pici

60356001 - Fortaleza, CE - Brasil 